\title{
The Patients' Liaison Group
}

\author{
Linda Lamont (The Patients' Association); and Brice Pitt (Chair, Patients' Liaison \\ Group)
}

The Royal College of Psychiatrists formed a Patients' Liaison Group in 1991 which has (at the time of writing) met seven times. As far as we know, only one other Royal medical college (that of the General Practitioners) has one. Modelled, in the first instance, on the RCGP committee, the Group met first in April 1991 with the aims of:

(a) making the College aware of patients' concerns

(b) considering ways of achieving consistent and equitable quality of treatment and care for all those who need it.

It was to provide a forum for a continuing dialogue between psychiatrists, patient groups and carers. There is as yet no firm constitution-it would be premature to create a rigid structure - although we agreed to meet three times a year, suggested that representatives serve for three years, and would not want more members than can debate round a table.

Brice Pitt, the College's Director of Public Education, is Chair. The President, a Vice-President, the Chair of the Public Policy Committee, and representatives of the Public Education and the Collegiate Trainees' Committee are the psychiatrists in the Group. The patient and carer representatives are from the Patients' Association, MIND, the Manic Depression and National Schizophrenia Fellowships, Mencap, Rescare, Action for the Sick Child, Age Concern, the Alzheimer's Disease Society, the Carers' National Association, Survivors Speak Out, Young Minds and the Association of Community Health Councils. Steps are being taken to increase the involvement of patient users of psychiatric services, as the Group has been somewhat 'advocate dominated'. The College's Secretary Vanessa Cameron, who had much to do with bringing the Group into being), the Public Education
Officer (Deborah Hart) and the Group's secretary (Chris Gear) also attend.

The work has been constructive. The agenda is set by concerns expressed by the patient/carer representatives, as well as by topics on which the Chair and College committees (notably the Executive and Finance, the Public Policy and the Public Education) would like the Group's views. Issues of consent (with special reference to Law Commission's consultation paper on Mentally Incapacitated Adults and Decision Making), the plight of mentally disordered offenders (with particular regard to the Reed Committee's report), advocacy, 'users' (with discussion of the MIND policy document on user involvement), patients' access to their records, mixed-sex wards, and doctors' attitudes have been to the fore. The Group has commented on prescription charges, the Patients' Charter, The Health of the Nation and The Mental Health of the Nation, the appropriateness of the label 'manic depressive psychosis' and the proposed Community Supervision Order. The Group discussed the 'Help is at Hand' leaflets on Bereavement, Surviving Adolescence, Sleep Problems and Depression in Old Age before their publication and the Patients' Factsheets. The Group nominated members to serve on the 'Defeat Depression Campaign', and the consensus on the Use of High Dose Antipsychotic Medication.

Three meetings a year are not many: we need to continue our liaison between meetings. We might also set up one-day or half-day meetings addressing specific subjects, in association with the appropriate College section or group.

We have established a network which is available both to the College and to the patient organisations represented within the Group. Its potential is far more than has so far been realised. 